\title{
RANCANG BANGUN WEBSITE TRACER ALUMNI AKN PUTRA SANG FAJAR BLITAR
}

\author{
M. Nur Fu'ad, M.Kom ${ }^{1)}$, Adimas Ketut N., M.Kom²), dan Elok Hastari C., S.Kom ${ }^{3)}$ \\ ${ }^{1,2,3)}$ Administrasi Server dan Jaringan Komputer, Akademi Komunitas Negeri Putra Sang Fajar Blitar \\ e-mail: nurfuadmail@gmail.com ${ }^{1)}, \underline{\text { dimas@akb.ac.id }}{ }^{2}$, elok.chan@gmail.com $^{3)}$
}

\begin{abstract}
Abstrak : Tracer study merupakan suatu metode yang digunakan untuk menadapatkan umpan balik dari alumni ke Perguruan Tinggi. Tracer alumni dapat dimanfaatkan untuk mengetahui keterserapan alumni AKN PSF Blitar dalam dunia usaha maupun industri. Selain itu juga sebagai acuan penyesuaian kompetensi yang harus dimiliki calon alumni AKN PSF Blitar sesuai dengan kebutuhan dunia usaha dan industry. Pengembangan sistem menggunakan metode waterfall yang memiliki beberapa tahap, diantaranya yakni perencanaan, analisis, perancangan, implementasi, dan pengujian. Teknologi yang digunakan dalam sistem ini adalah berbasis web yang bertujuan untuk memudahkan user dalam pengisian kuisioner dan dapat lebih luas jangkauannya. Hasil dari rancangan sistem ini adalah desain sistem yang menggunakan use case, alur sistem menggunakan flowchart dan perancangan physic data model. Hasil yang diperoleh adalah sistem yang berbasis web dapat menjangkau user yang lebih luas, sistem ini mengurangi biaya operasional, pembatasan hak akses serta laporan individu alumni.

Kesimpulan: Sistem ini dapat membantu Perguruan tinggi dalam melakukan tracer study dengan mudah. Sistem yang digunakan berbasis web yang dapat menjangkau alumni dimanapun berada sehingga alumni tidak perlu dating ke kampus atau mengirimkan data kuisionernya sehingga data akan lebih cepat untuk diproses.
\end{abstract}

Kata Kunci-Tracer Study, web, alumni, waterfall

Abstract : Tracer study is a method used to get feedback from alumni to tertiary institutions. Tracer alumni can be used to determine the absorption of PSN Blitar AKN alumni in the business world and industry. In addition, it also serves as a reference for adjusting competencies that must be owned by prospective alumni of AKN PSF Blitar in accordance with the needs of the business world and industry. System development uses the waterfall method which has several stages, including planning, analysis, design, implementation, and testing. The technology used in this system is web-based which aims to facilitate users in filling out the questionnaire and can be wider in scope. The result of this system design is a system design that uses a use case, the system flow uses a flowchart and the design of the physic data model. The results obtained are a web-based system that can reach a wider user, this system reduces operational costs, restrictions on access rights and individual alumni reports.

Conclusion: This system can help universities in conducting tracer studies easily. The system used is web-based which can reach alumni wherever they are so that alumni do not need to come to campus or send questionnaire data so that the data will be faster to process.

Keywords - Tracer Study, web, alumni, waterfall

\section{PEndahuluan}

7 racer alumni merupakan salah satu metode yang digunakan untuk mendapatkan umpan balik dari alumni perguruan tinggi. Dalam upaya untuk pengembangan serta perbaikan kualitas dan sistem pendidikan perguruan tinggi umpan balik ini sangat dibutuhkan. Selain itu umpan balik dari alumni juga bermanfaat dalam pemetaan dunia usaha dan industri untuk mengetahui tuntutan dunia kerja terhadap kompetensi yang diajarkan pada waktu kuliah.

Pada laman web tracer studi Kementerian Riset, Teknologi dan Pendidikan Tinggi, tracer alumni yang juga disebut sebagai tracer study dinilai penting karena menjadi alat evaluasi kinerja Perguruan Tinggi dan sekarang telah dijadikan salah satu syarat kelengkapan akreditasi oleh Badan Akreditasi Nasional Perguruan Tinggi (BAN-PT), sebagai kelengkapan dalam dokumen Evaluasi Diri. Hasil tracer study akan membantu Perguruan Tinggi dalam mengetahui posisi lulusan yang telah terserap dalam dunia kerja serta menyiapkan lulusan sesuai dengan kompetansi yang diperlukan di dunia kerja (http://pkts.belmawa.ristekdikti.go.id). 
Akademi Komunitas Negeri Putra Sang Fajar Blitar (AKN PSF Blitar) sebagai salah satu perguruan tinggi negeri di lingkungan Kementerian Riset, Teknologi dan Pendidikan Tinggi juga menganggap penting tracer alumni. Tracer alumni dapat dimanfaatkan untuk mengetahui keterserapan alumni AKN PSF Blitar dalam dunia usaha maupun industri. Selain itu juga sebagai acuan penyesuaian kompetensi yang harus dimiliki calon alumni AKN PSF Blitar sesuai dengan kebutuhan dunia usaha dan industri.

Namun hingga saat ini masih belum tersedia suatu sistem tracer alumni pada AKN PSF Blitar yang sudah tersistem dengan baik. Sistem pendataan tracer alumni pada AKN PSF Blitar sebelumnya dilaksanakan dengan mengisi angket yang disebarkan kepada alumni ketika datang ke kampus AKN PSF Blitar. Kemudian alumni mengisi angket dan diserahkan kembali ke kampus AKN PSF Blitar.

Berdasarkan sistem yang lama, terdapat kekurangan yakni angket hanya diisi oleh alumni yang berkunjung ke kampus sedangkan yang tidak pernah berkunjung ke kampus tidak mengisi angket. Kemudian terkadang alumni yang berkunjung ke kampus tidak mengisi angket karena petugas sedang tidak tersedia maupun angketnya sedang belum digandakan lagi. Angket yang masih ditulis di kertas pun menjadi masalah karena datanya tidak ditindak lanjuti karena belum terkomputerisasi sehingga hanya disimpan saja.

Berdasarkan permasalahan tersebut, peneliti berinisiatif melakukan perancangan web tracer alumni yang akan menjadi dasar pembuatan sistem tracer alumni AKN PSF Blitar. Web tracer alumni yang dirancang harus dapat tersedia secara online sehingga meskipun tidak berkunjung ke kampus namun alumni dapat melakukan pengisian tracer alumni.

\subsection{Aplikasi Web}

\section{TINJAUAN PUSTAKA}

Aplikasi web adalah adalah suatu aplikasi yang diakses menggunakan penjelajah web melalui suatu jaringan seperti Internet atau intranet. Aplikasi web dibagun menggunakan bahasa pemrograman web. Pemrograman web merupakan bahasa pemrograman untuk memnghasilkan aplikasi komputer yang dapat digunakan atau ditampilkan dengan bantuan browser. Dalam pemrograman web, pengembang harus menginstal aplikasi web server. Salah satu web server yang sering digunakan adalah apache (Martono, 2013). Banyak keuntungan yang diberikan oleh Aplikasi berbasis Web daripada aplikasi berbasis desktop, sehingga aplikasi berbasis web telah diadopsi oleh perusahaan sebagai bagian dari strategi teknologi informasinya, karena beberapa alas an seperti akses informasi mudah, setup server lebih mudah, informasi mudah didistribusikan dan bebas platform.

2.2 Tracer Alumni

Trace alumni dinilai penting karena menjadi alat evaluasi kinerja Perguruan Tinggi dan sekarang telah dijadikan salah satu syarat kelengkapan akreditasi oleh Badan Akreditasi Nasional Perguruan Tinggi (BAN-PT), sebagai kelengkapan dalam dokumen Evaluasi Diri yang diperlukan dalam pengajuan proposal akreditasi. Mengutip dari laman resmi tracer studi Kemenristekdikti, tracer alumni ditujukan untuk melacak jejak lulusan/alumni yang dilakukan setelah lulus dan bertujuan untuk mengetahui:

a. Outcome pendidikan dalam bentuk transisi dari dunia pendidikan tinggi ke dunia kerja (termasuk masa tunggu kerja dan proses pencarian kerja pertama), situasi kerja terakhir, dan aplikasi kompetensi di dunia kerja.

b. Output pendidikan yaitu penilaian diri terhadap penguasaan dan pemerolehan kompetensi.

c. Proses pendidikan berupa evaluasi proses pembelajaran dan kontribusi pendidikan tinggi terhadap pemerolehan kompetensi.

\section{Metode PENELitian}

\subsection{Metode Penelitian}


Aplikasi sebelum dapat digunakan, harus dirancang terlebih dahulu dengan seksama agar dapat beroperasi secara optimal. Perancangan aplikasi secara umum dapat menggunakan metode perancangan Classic Life Cycle atau Waterfall Model. Metode perancangan Waterfall Model memiliki beberapa tahap, diantaranya yakni perencanaan, analisis, perancangan, implementasi, dan pengujian (Diana \& As'ad, 2017).

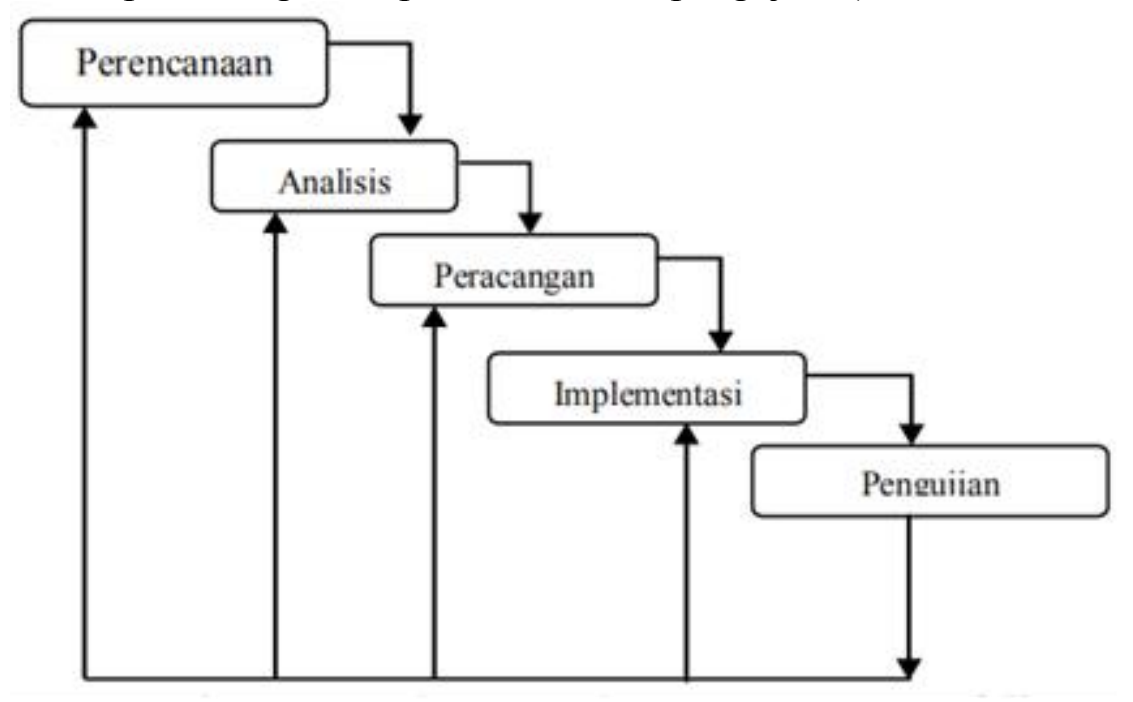

Gambar 1. Metode Waterfall

Tahapan Perencanaan bertujuan untuk memberi rambu-rambu dalam mengembangkan aplikasi agar sesuai dengan tujuan penggunaanya kelak. Dalam tahapan perencanaan juga dilakukan pembatasan atas apa yang boleh dan tidak boleh dilakukan pada pembuatan aplikasi. Kemudian dilanjutkan dengan tahapan analisis yang bertujuan untuk mendapatkan pemahaman secara keseluruhan tentang aplikasi yang akan dikembangkan berdasarkan masukan dari calon pengguna. Selanjutnya diteruskan dengan tahapan perencanaan yang di dalamnya termasuk penentuan bentuk arsistektur aplikasi yang memenuhi semua perencanaan non fungsional dan batasan teknologi, pembuatan abtraksi yang tak terlihat pada implementasi aplikasi dan menyediakan visualisasi implementasi.

Setelah melalui tahapan perencanaan, analisis dan perancangan, maka apliksi siap diimplementasikan. Pada tahapan implementasi dilaksanakan beberapa tugas, antara lain, implementasi desain ke dalam komponen-komponen source, code, script, executable dan sebagainya, kemudian menyempurnakan arsitektur dan mengintegrasikan komponen-komponen (mengkompile dan link ke dalam satu atau lebih executable) untuk integrasi dan testing system. Terakhir sebelum aplikasi resmi digunakan, dilaksanakan tahapan pengujian. Pada tahapan pengujian, aplikasi diuji untuk menentukan apakah sudah mampu menjalankan semua operasi sesuai tahapan perencanaan dan analisis.

\subsection{Analisa Kebutuhan}

Spesifikasi kebutuhan sistem terdiri dari beberapa kebutuhan fungsional dan kebutuhan non-fungsional.

\subsubsection{Kebutuhan Fungsional}

Berikut adalah kebutuhan fungsional dari website ini :

1. User dapat melakukan login

2. Alumni dapat mengisi form tracer study

3. Admin dapat mengelola data user.

\subsubsection{Kebutuhan Non Fungsional}

Berikut adalah kebutuhan fungsional dari website ini :

1. Dapat di akses secara publik.

2. Website ini dapat di akses ke semua platform.

3. Website dapat digunakan untuk mengisi tracer study. 


\subsection{Desain Sistem}

Proses desain merupakan terjemah dari Analisa kebutuhan ke sebuah perancangan perangkat lunak agar mempermudah dalam membangun sistem. Desain sistem pada penelitian ini menggunakan use case diagram. Use case diagram merupakan pemodelan untuk perilaku sistem yang akan dibuat. Use case mendeskripsikan sebuah interaksi antara satu atau lebih actor dengan sistem yang akan dibuat (A. S. \& Salahudin, 2013). Pada diagram ini akan mendeskripsikan tipikal interaksi antara admin dengan mahasiswa sebagai user. Use case diagram dapat dilihat pada gambar di bawah ini :

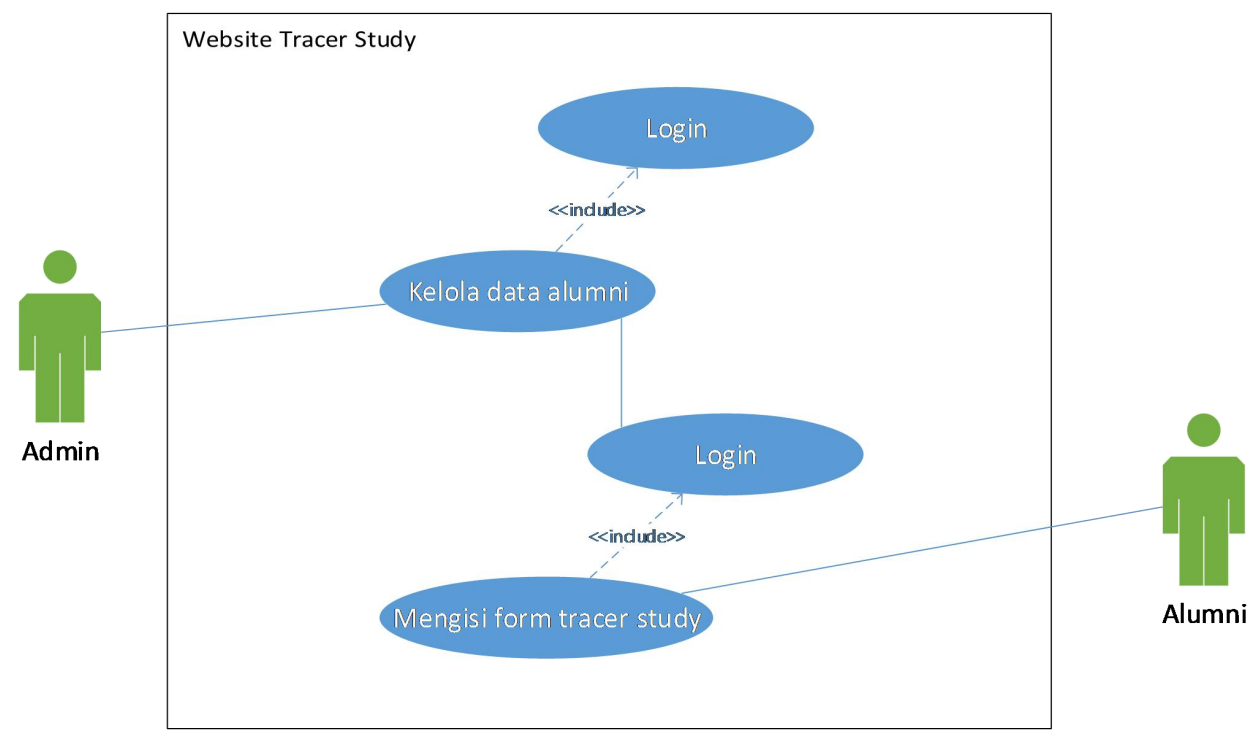

Gambar 2. Use Case Sistem

\subsubsection{Flowchart}

Dalam sistem ini terdapat dua proses alur sistem, yaitu alur input data alumni dan input data kuisioner tracer study. Untuk menggambarkan urutan proses secara detail dan hubungan suatu proses dengan proses lainnya, maka dalam sistem ini dibuat flowchart. Alur flowcart pada sistem ini dapat dilihat pada gambar di bawah ini :

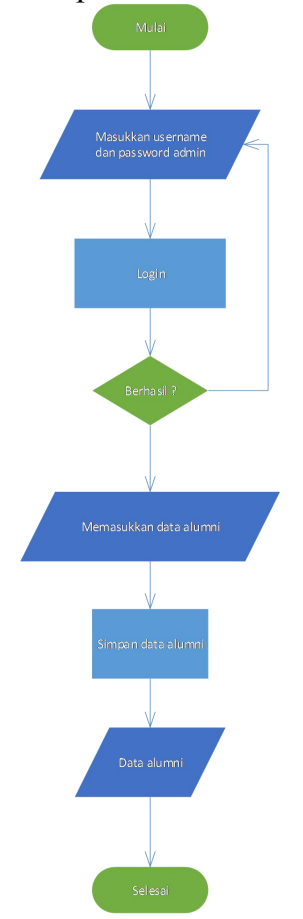

Gambar 3. Flowchart input data alumni

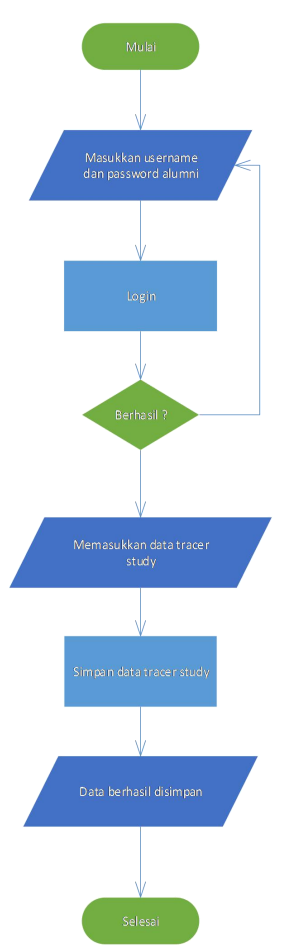

Gambar 4. Input data tracer studi

\subsection{Desain Databasse}


Pada aplikasi tracer study terdapat 5 tabel yaitu table login, data alumni, kuisioner1, kuisioner2 dan kuisioner3. Untuk Physic Data Model dapat dilihat pada gambar dibawah ini :

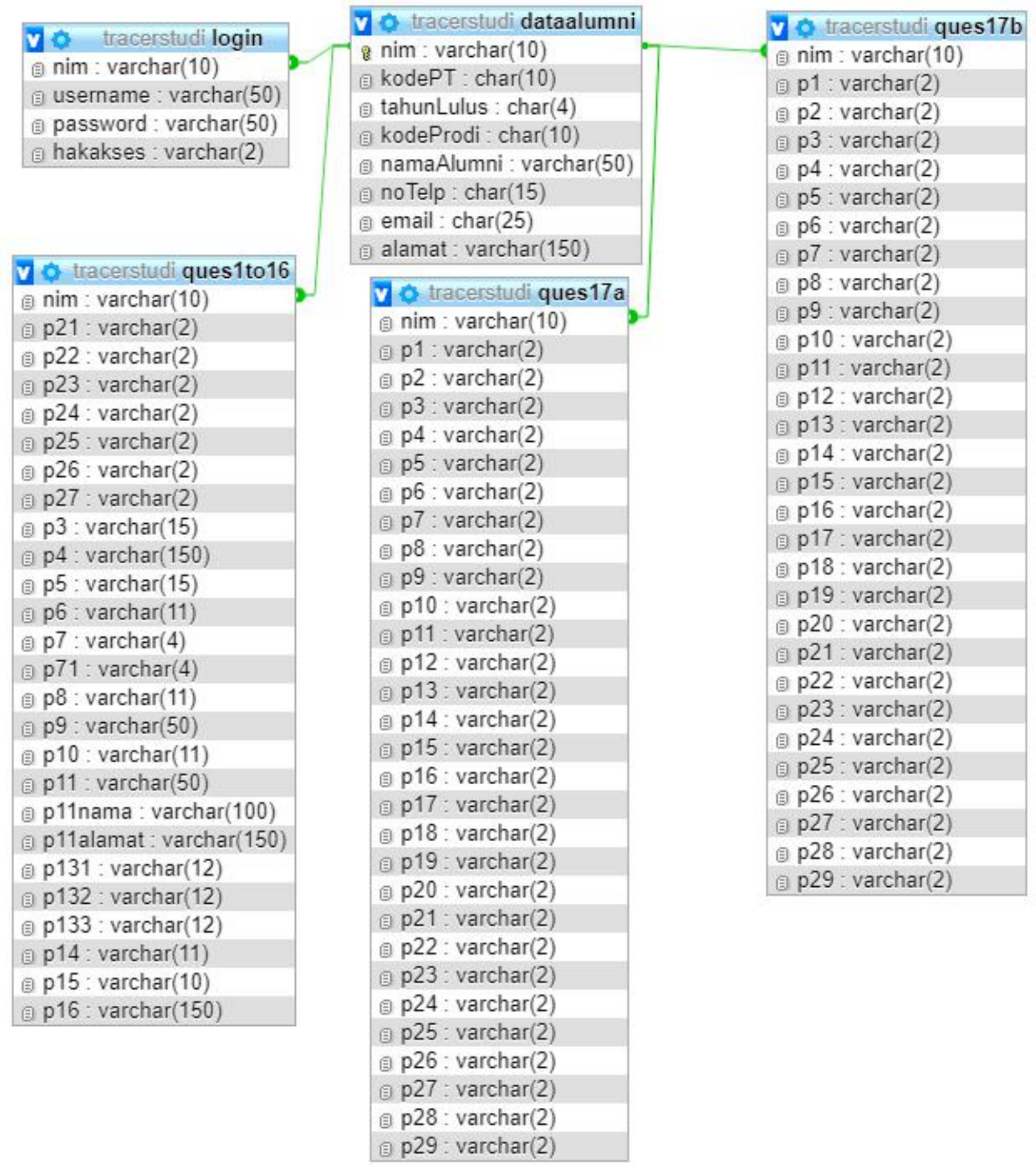

Gambar 5. Physical Data Model

\section{HASIL DAN PEMBAHASAN}

\subsection{Implementasi}

Sistem tracer study di Akademi Komunitas Negeri Putra Sang Fajar Blitar merupakan sistem yang berbasis web. Sistem ini dapat diakses oleh stake holder yang lebih luar serta pengisian kuisioner dapat lebih cepat. 
Sistem ini diakses oleh dua user yaitu admin dan alumni. Fungsi dari form login untuk membagi hak akses ke tiap user berdasarkan username dan password masing-masing. Setelah memasukkan user dan password pad field yang telah disediakan, kemudian tekan tombol login. Sistem akan mengecek account yang telah terdaftar, maka sistem akan mengarahkan ke halaman masing-masing user, namun jika ada yang belum terdaftar maka sistem akan menolaknya. Berikut adalah tampilan form login di sistem ini :

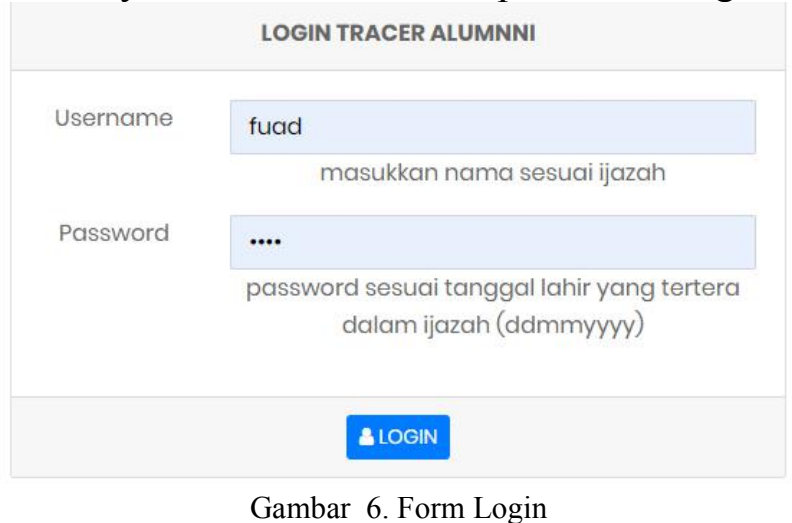

Setelah login maka sistem akan mengarahkan ke halaman kuisioner yang digunakan untuk memasukkan data kuisioner alumni. Form kuisioner ini hanya dapat diakses oleh alumni dengan masing-masing user dan password. Form pengisian kuisioner alumni digunakan untuk menjawab pertanyaan tracer study yang dibagi menjadi 2 tahapan. Tahap pertama untuk mengisi data identitas alumni yang terbaru. Sedangkan tahap kedua untuk mengisi kuisioner riwayat pekerjaan, lama tunggu bekerja dan kesesuaian materi kuliah dengan bidang kerja.

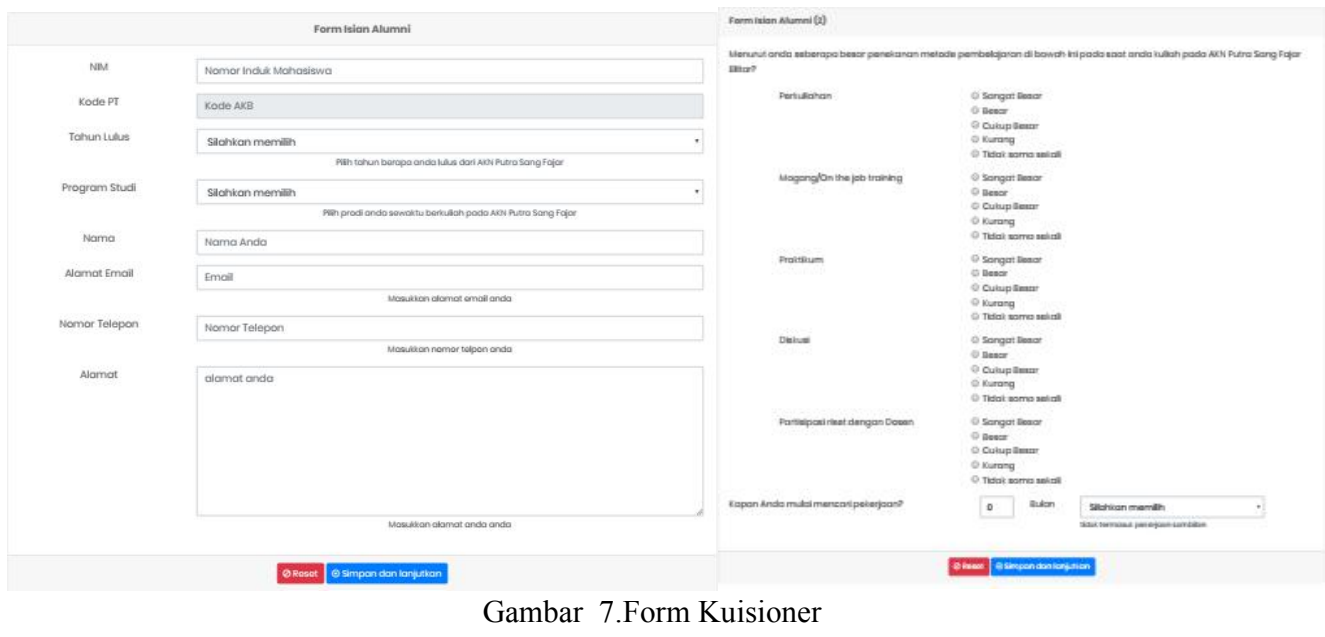

Dalam sistem ini hanya menampilkan laporan isian per alumni saja belum menampilkan grafik hasil rekapitulasi hasil isian kuisioner tracer study. Grafik ini digunakan untuk pelaporan hasil untuk membantu pimpinan lebih mudah dalam menyajikan data yang dapat digunakan sebagai alat pengambil kebijakan perguruan tinggi.

\subsection{Pengujian Sistem}

Pengujian sistem bersifat fungsional sistem. Pada penelitian ini ujicoba sistem menggunakan metode black box untuk menguji dan menilai fungsional sistem. Uji coba ini dilakukan dengan cara memasukkan data pada isian pada form dan penggunaan data pada form. 


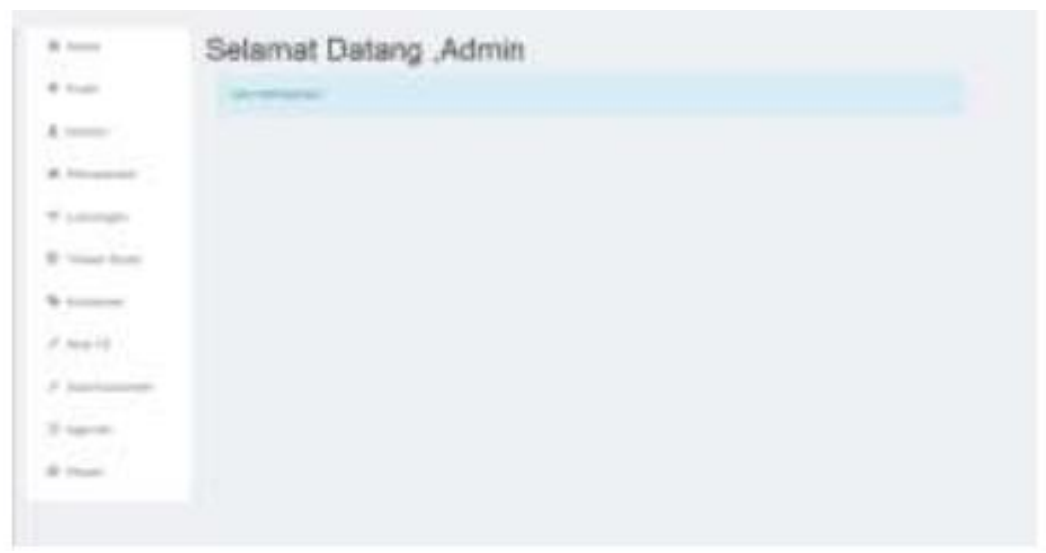

Gambar 8. Tampilan setalah login berhasil

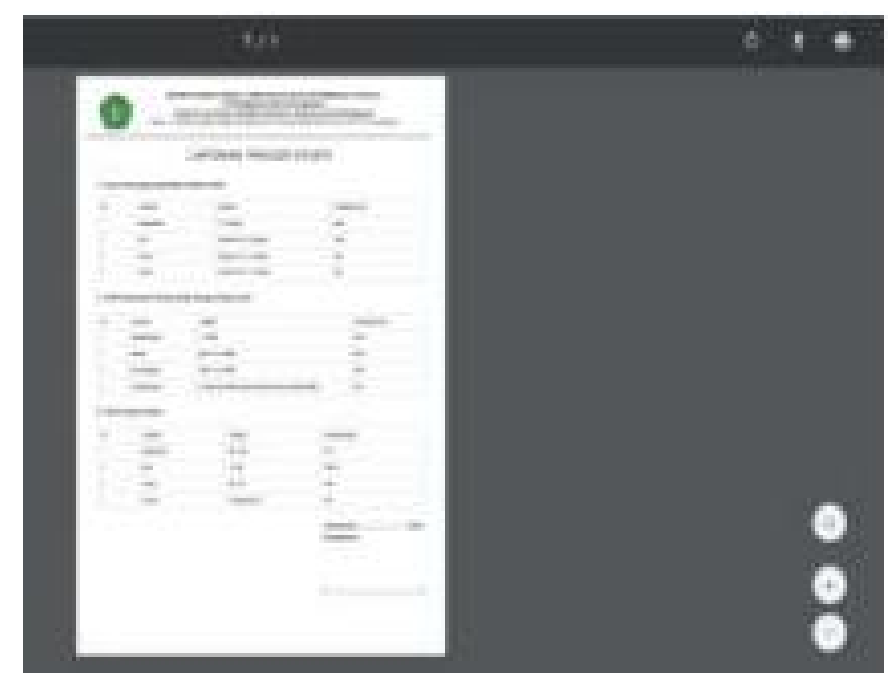

\subsection{Pengujian Usability}

Gambar 9. Tampilan setalah berhasil memasukkan data tracer study

Pengujian usability adalah pengujuan yang dilakukan untuk mengetahui tingkat kemudahan pengguna dalam menggunakan aplikasi tracer studi ini. Pada pengujian ini menggunakan kuisioner USE Questiomaire dengan penyajian hasil menggunakan skala likert. Dalam kuisioner ini terdiri dari 30 item soal yang mewakili pengguna untuk mendiskripsikan tinggal usability sistem e-tracer study.

Populasi dan sample dalam penelitian ini berjumlah 70 alumni. Untuk menentukan sample dari alumni menggunakan rumus slovin yaitu sebagai berikut :

$$
\begin{gathered}
\mathrm{N}= \\
\text { Ket }: \\
\mathrm{N}=\text { Ukuran populasi } \\
\mathrm{n}=\text { Ukuran sample } \\
1=\text { Bilangan konstan } \\
\mathrm{e}=\text { tingkat kesalahan }
\end{gathered}
$$

$$
\mathrm{N}=
$$




\subsection{Kesimpulan}

\section{KESIMPULAN}

Berdasarkan hasil evaluasi sistem tracer study di Akademi Komunitas Negeri Putra Sang Fajar Blitar ini dapat diambil beberapa kesimpulan, yaitu :

1. Dengan adanya sistem tracer studi ini memberikan kemudahan untuk administrator akademik untuk mengelola adata alumni serta evaluasi kinerja lulusan Akademi Komunitas Negeri Putra Sang Fajar Blitar.

2. Memudahkan alumni untuk melakukan pengisian form tracer studi karena bisa dilakukan kapan saja dan dimana saja.

3. Memudahkan stakeholder dalam memberikan evaluasi kinerja perguruan tinggi.

4. berdasarkan ujicoba sistem diperoleh hasil bahwa semua fasilitas sistem dapat digunakan dengan baik.

5. Berdasarkan evaluasi dengan kuisoner dapat dianalisis dari 30 responden, sebanyak $80 \%$ menyatakan bahwa sistem tracer studi merasa sangat baik, 11\% merasa cukup baik dan 9\% merasa kurang baik.

\subsection{Saran}

Saran yang dapat diberikan untuk pengembangan penelitian atau peneliti selanjutnya, sebagai berikut :

1. Untuk memaksimalkan pengisian tracer studi perlu adanya sosialiasi tentang sistem ini. Sehingga alumni yang tersebar jauh di daerah dapat mengetahui manfaat dari sistem ini serta timbul kesadaran untuk mengisi tracer study.

2. Selalu menjalin hubungan yang baik dengan stakeholder aggar dapat memberikan masukan untuk pengembangan sistem yang berkelanjutan.

3. Dalam proses pengembangan dan pemeliharaan sistem dilakukan sesuai dengan kebutuhan.

4. Selalu melakukan back-up database secara teratur dan berkala untuk menjaga data-data dapat terjaga dengan baik dan tersimpan dengan aman apabila ada kerusakan pada perangkat keras maupun sistem.

\section{UCAPAN TERIMA KASIH}

Ucapan terima kasih diberikan kepada segenap keluarga besar Akademi Komunitas Neger Putra Sang Fajar yang telah mensuport penuh tim peneliti sehingga dapat menghasilkan karya yang bermanfaat bagi yang membutuhkan.

\section{DAFTAR PUSTAKA}

[1] Diana, Elviza dan As'ad. (2017). “Analisis Dan Perancangan Sistem Informasi Tracer Study Berbasis Web”. Jurnal MEDIASISFO, Vol. 11, No. 2.

[2] Hendrastomo, Grendi et al. (2015). "Studi Eksplorasi Tingkat Kepuasan Pengguna Lulusan Program Studi Pendidikan Sosiologi”. Penelitian Internal Fakultas Ilmu Sosial dan Ekonomi, Universitas Negeri Yogyakarta.

[3] Hidayati, Anisa Nur. (2014). “Analisis Perancangan Sistem Informasi Tracer Study Berbasis Web Dengan Menggunakan Codeigniter”. Skripsi, Program Studi Pendidikan Teknik Informatika Fakultas Teknik Universitas Negeri Yogyakarta.

[4] Karyoto, Giat dan Hermanto, Nandang. (2013). "Rancang Bangun Sistem Tracer Study Online pada STMIK AMIKOM PURWOKERTO”. Seminar Nasional Teknologi Informasi \& Komunikasi Terapan 2013 (SEMANTIK 2013), Semarang, 16 November 2013.

[5] Martono, Kurniawan Teguh. (2013). "Tracer Alumni berbasis Website (Kasus : Sistem Komputer Fakultas Teknik UNDIP)”. Jurnal Sistem Komputer, Vol. 3, No. 1. 